\title{
Learning from Our Mistakes: International Educators Reflect
}

\section{David Shallenberger}

School for International Training

\begin{abstract}
"By seeking and blundering we learn."
(Johann Wolfgang von Goethe)

"The only real mistake is the one from which we learn nothing."

(Henry Ford)

"Freedom is not worth having if it does not include the freedom to make mistakes"

(Mahatma Gandhi)

"Non enim omnis error stultitia est dicenda"

(We must not say every mistake is a foolish one.)

(Marcus Tullius Cicero)

"He who knows much makes many mistakes."

(Turkish proverb)

"Omul invata gresind" (The man learns by making mistakes)

(Romanian proverb)

"A known mistake is better than an unknown truth"
\end{abstract}

(Arabic proverb)

\section{Introduction}

It is commonly accepted that we should and often do learn from our mistakes, as the proverbs from around the world show. The self-help, scientific, and business management literature is full of guidance in this regard (Schoemaker, 2011; McGregor, 2006; Lehrer, 2009; Livio, 2013; Holden, 2007; Ullsperger, 2008; Tugend, 2011; and the entire April 2011 issue of Harvard Business Review). From Cicero to Gandhi, and Romania to China, received wisdom tells us that we should honor our mistakes, that they can lead us to great learning.

It is also quite common to be afraid of making mistakes. Teachers grade us down for errors on tests, bosses often chastise us (and worse) for taking risks, and religions may condemn us if we commit a sin or take the wrong path. Popular and academic literature on perfectionism (Antony \& Swinson, 2009) and research such as that done by Accountemps (2012) on workplace fears substantiate the commonness of this fear of making mistakes.

International educators are no exception to the experience of learning from mistakes. At a recent 
professional meeting, several of us who had been in the field for decades shared some of our greatest lessons reaped from mistakes. As people who cross borders regularly we could cite multiple instances of funny and serious cultural and linguistic misunderstandings, using the wrong word and offending someone, for example. At the same time, and particularly at earlier phases in our careers, we had been embarrassed by our mistakes.

At the gathering mentioned above these cultural gaffes were common, but so were mistakes we had made in working with students, bosses and coworkers: not listening carefully to all sides of a problem, rushing to conclusions, making poor decisions, and so on.

This conversation and others led me to wonder about the larger field, and to ask the question of others, "What have you learned from your professional mistakes?" This article comes out of that research.

\section{Researcher Reflection}

Perhaps because I am approaching retirement, I do not worry about sharing my own mistakes. In fact, as an educator who works with graduate students in international education, I share these tripups regularly, to help them feel comfortable. As a consultant, I also own the mistakes I've made as a way to be honest and to explore the range of alternatives and possible outcomes that can emerge out of strategic work. So I will share a few mistakes in my own life that have helped me learn.

- On a short-term program I was leading in Switzerland, I was surprised to see an African American student come back early from a free weekend. I asked him about his return and he told me of a frustrating encounter he had in Milan, which he attributed to racism. Instead of hearing him out, I jumped in quickly to challenge him about possible cultural factors and misunderstandings. My intervention stopped his processing and sharing in its tracks. My lesson: listen without judgment.

- I was tasked with developing and implementing an undergraduate degree program in Hong Kong for a US-based university. I had many important lessons along the way, beginning with my first day when I sat on the edge of the desk and asked for ideas and input in a context that disdained that kind of overly casual behavior on the part of a professor. You'd think I would have learned better after five years, but that's when I had a room of US American and Hong Kong Chinese students together studying power and privilege in their two societies. I asked the Chinese women to form a fishbowl to discuss stereotypes about women in Hong Kong - with no volunteers. My lesson: fully integrating cultural learning is difficult and requires constant reminders; hierarchy and power mean very different things in other cultures.

- Trying to pull together a large enough group to run a short-term program, I invited a former participant from a trip I had led a couple years before, who I knew had maintained strong connections with one of the countries we were visiting. My "gut," however, told me that inviting him would be a mistake, since his overbearing style had created many problems in the earlier group. Sure enough, he turned out to be difficult in many ways. My lesson: don't waive your criteria out of desperation in order to have enough students to make the program viable.

Of course there are many smaller mistakes I, like many others, have made. On numerous occasions I have gone into a store to buy something, asked for what I wanted (after carefully preparing my question in the local language), and received a rather curt response because I did not go through 
the accepted gracious openings expected in other cultures. My US American hurried mentality has betrayed me and, by not asking first how the shopkeeper is, I have been seen as rude. In a similar vein I have sought firm appointments for meetings when I've been traveling in countries where the rhythm is much more relaxed, and I'm afraid my impatience and frustration have been too visible. I've been seen as pushy and obsessive, working counter to my goals. My lesson: be aware of cultural norms and act respectfully. In situations like those mentioned above, take a breath and move slowly.

In a similar vein, I can't even begin to count the number of linguistics mistakes I've made when I've ventured into communication in the host language. But the biggest mistake in this regard has been NOT taking the risk to speak because I was embarrassed or afraid of looking like an idiot.

\section{An interdisciplinary and cross-disciplinary idea}

Much has been written about making mistakes and learning from them. Mistakes have been important in advancing scientific discovery (for example, Livio, 2013). Similarly, scholars of learning organizations beginning, perhaps with Senge (1990), and decision scientists such as Schoemaker (2011) make a similar statement about how creating room for mistakes can be profitable. There is also a rich body of literature of reflective practice and teaching, stimulated by educators such as Schon (1984) and Palmer (1997). The insight, research and reflection are inter- and cross-disciplinary, and much too vast to cover here, so I will merely acknowledge and briefly synthesize some key points. In this cumulative work, three of the most significant benefits of mistake-making stand out:

- Most clearly, mistakes make way for important learning and innovation, because they take us outside of normal pathways.

- Making room for mistakes creates a culture of support and camaraderie.

- Mistakes can set off a line of thinking that opens up new ways of thinking about an issue.

Mistakes and learning in International Education.

In this field, there has been an understandable focus on intercultural misunderstandings. There are numerous books, videos and other materials such as Molinsky (2013), Peace Corps (2010), the Culture Smart series of almost 100 titles (including, for example, Williams \& Branco, 2014), and Kwintessential's web articles (Kwintessential, 2014) on "cultural gaffes." These are mostly geared toward avoiding mistakes, but also, almost as an afterthought, they include advice on how to deal with them once you commit them.

Perhaps most directly relevant to this discussion is research sponsored by The Forum on Education Abroad on the challenges that beset partnerships between Brazilian and US American international educators (2013). Prepared for a dialogue at the 2013 FAUBAI (Brazilian international education) conference, the research identified the following difficulties and misunderstandings:

- US Americans were frustrated by strikes, lack of responses to emails, changing personnel, and the difficulty of making appointments. They typically attributed the last three to lack of interest on the part of potential Brazilian partners.

- Brazilians felt Americans only cared about money, were not genuinely interested in Brazil or Portuguese, and did not understand the country. 
By understanding the two societies, one can see the cultural and social factors at play. It is understandable, for example, that communication between high-context Brazilians and low-context US Americans would encounter significant snags. Add to that the very different structures within educational institutions, and one can see great potential for frustration. Participants in the dialogue felt the conversation was worthwhile, and saw the mistakes in their assumptions about the other culture, but that does not mean that one will see change immediately in how international educators from the two cultures see and work with each other. These kinds of challenges are very difficult to uproot.

Many of us are all too familiar with the bigger mistakes, as reflected in the legal cases lost by providers and institutions, that have led to headlines and concerns about risk management. Among the most famous cases are Panena v. CAPA, Bird v. Lewis and Clark College, King v. Eastern Michigan University, and Fay v. Thiel College (Hoye, 2006, for a discussion of these cases). And we all know through the grapevine about other incidents, ranging from vehicle accidents to student deaths, that may reflect mistakes. Certainly there are multiple perspectives on all of these situations, and fault does not necessarily lie solely with the provider or the institution. That said, they do cause one to think about how one can facilitate study abroad without such calamities, i.e., minimizing mistakes. And they provide lessons to us about what can go wrong and suggest steps we might take to avoid situations like these in the future.

Thankfully, such grave problems are rare. Our work does entail risk on a range of levels and mistakes can be more or less costly. Schoemaker (2011) presents a typology that presents costs and potential benefits of mistakes, and identifies "brilliant mistakes" as those having low cost and high benefits. Examples he cites include a lab error that leads to a new discovery or the loss of a job that results in a new career. Schoemaker goes on to add that these benefits typically take years to develop and that it's often impossible to tell at the time of making the mistake that it was a "brilliant" one.

\section{This Project}

\section{Methods}

Participants in this project came through requests made on international education listservs. In the end 40 people answered an online qualitative survey and twelve people were interviewed for deeper insight and information. In five cases, interviewees did not participate in surveys first, so a total of 45 persons participated in the study. Responses were identified with codes that emerged directly from the data.

The format of the surveys and interviews was simple. I asked participants, after they shared an overview of their professional trajectory, to tell me about one to three mistakes in their professional lives that led to significant learning for them. The interviews yielded very rich reflections, but even the surveys were qualitative in nature and contained meaningful reflection.

Participants were international educators who brought a significant level of experience:

\begin{tabular}{|l|l|}
\hline Less than one year & $0 \%$ \\
\hline $1-3$ years & $2.5 \%$ \\
\hline
\end{tabular}




\begin{tabular}{|l|l|}
\hline $4-10$ years & $35 \%$ \\
\hline $11-20$ years & $40 \%$ \\
\hline More than 20 years & $22.5 \%$ \\
\hline
\end{tabular}

Their roles spanned the field, and many had moved across our typical categories, having worked with international students, study abroad, classroom teaching, and in other positions. Currently 20\% work in senior international positions, $17.5 \%$ work strictly with international students, $27.5 \%$ work in education abroad, and the remaining 35\% work in other roles from professor to alumni relations and student affairs. Whatever their specific role now, the participants' experience offers many lessons to education abroad professionals.

The research was approved by the Institutional Review Board of my institution.

\section{The Findings (Part 1)}

The lessons-from-mistakes tended to fall into six overlapping categories. In this article, I will focus on three of these areas that are particularly powerful; first, however, I will briefly describe the other three broad learnings, and I will bring these into the subsequent discussion when they contribute meaningfully.

Take the time and effort to build and maintain positive relationships. Our work as international educators is highly relational. It takes work to build relationships with students, partners, colleagues and others, but it is time well invested. Be wary of the temptation to succumb to the alltoo-frequent mountains of work and the temptation to not take this time for positive connections. Don't be afraid of conflict. Hear and consider everyone's voices at all times, but especially in times of conflict or distress. And if your organization is not a good fit, cut your losses and leave.

Culture is powerful and important. Have respect for it and consider it in every aspect of your work. We are constantly working across borders with people who bring different perspectives and worldviews to the interaction. We write social media postings, articles, letters and emails to people across the world and need to consider the variety of interpretations and responses our words can elicit. We teach and advise students who are in cultures not their own and we must help them see beyond the limits of their own "lenses," not to mention modeling this openness in our own behavior with others. Even after a lifetime of traveling and living abroad, we may continue to experience culture shock, which we should humbly honor.

Pay attention to procedures and operations. Have policies, communicate them clearly, and follow them; work scrupulously; attend to details; and know when to be flexible. Plan scrupulously, take a long-term perspective, and attend to the variety of countries and systems with which one interacts.

The Findings (Part 2)

Culture, relationships, and organizational operations, referenced above, are certainly key factors in our work and have an impact on the other three lessons that are discussed in the rest of this article. 
The findings explored below, however, are important reminders on their own, of how we should be doing our work:

1. Trust your gut and be careful about assumptions. Pay attention to "red flags." Investigate thoroughly.

2. Design strong student-centered programs that take advantage of the location, and which are holistic, reflective and experiential.

3. It is important to take care of yourself, to seek and maintain balance.

Overarching lesson: Trust your gut and be careful about assumptions. Pay attention to "red flags." Investigate thoroughly. Evaluating options and making decisions are rarely simple, requiring a balance between intuition and investigation. I have grouped participant responses in three categories to show the richness of thought and honor the focus of the respondents, but the ideas clearly overlap.

Mistake: Not trusting your "gut," especially when you note a "red flag." Sometimes we just have a sense of what's right in the particular circumstance, but we ignore that insight and make another choice. In one example, an individual

... allowed [a] proposal for [a] million dollar program development grant to go forward when there was no student interest in the geographical area for the program [because it was] pushed by faculty and upper administration. [It] failed miserably and was a nightmare to administer.

Sometimes, the intuition is about an individual - a student, a provider, or a colleague. With respect to the latter, see what one respondent said about a recurring observation:

In numerous situations I allowed "logic" to override my gut feelings on things, particularly as it related to new hires. Every time I looked back I realized that I had an instinct about it from the start, but didn't trust my gut.

A similar realization came to another participant in the study, this time with respect to a service provider:

I had a 'bad feeling' about possibly working [with] a new service provider in spite of positive feedback from other professionals that had worked with this service provider... . The relationship with this service provider fell apart because they had changed their procedures/steps.

We have all had students who challenged us. Sometimes we had an inkling about problems that would ensue, even if there may have been little we could do about them. One individual, who worked in a study abroad office, had some unvoiced concerns about a student who was, in the end, accepted in a study abroad program and then sent home "for repeatedly engaging in behaviors dangerous to himself and others (he was sharing meds with other students on his program)." In another example, a resident director told me about a growing sense of discomfort around a particular student:

I had students on the program and one had been in the country before; surprisingly, he had almost visited all the places our program visits. He would tell students his expectations. I did 
not stop him in his tracks. He would give counter instructions, telling students they could swim when I told them they could not. I didn't realize the influence he was having. On every site visit, he would say that the lecturers were not good, that he had been here with his professors from university. At the end of it all, I noticed the other students were quiet and tense. I misread the situation - I thought they were tired, had drunk a lot. I had a gut feeling something was not right somewhere. My supervisor came around and spoke with the students and I discovered later from her that I did not have a good group of students, but that others loved the program. I had never had something like that. I need to learn how to nip it in the bud.

At times, there were clear "red flags," signs that we needed to pay attention, and the mistake was to ignore them. In the work of international educators, those signs may occur in numerous settings. For some respondents, one place was the job search process, during which we may have ignored indications that something was "not quite right." As one individual wrote, "I have glossed over "red flags' during initial interviewing processes or on application forms."

Red flags also appear in our work with students, and ignoring these may have powerful repercussions because of the intensity of our work with them. Ignoring students' jokes about drugs during pre-departure orientation, for example, may inadvertently contribute to a drug issue in country, as happened to one respondent. Another participant in the study notes that she has underestimated emails from students indicating potential concerns, which later proved to be real and important. In yet another situation, a student hid her history of anxiety during the application process, but the signs appeared during orientation when she was "disruptive and demanding:"

During the first few weeks I kept hoping she would relax and mellow out and instead she became increasingly agitated. I finally ended up losing my patience with her on excursion, which provided her with fuel for her anxiety and propelled her to try to get other students to join her in a campaign of disgruntlement. She eventually left the program [early] ...

As these individuals suggest, it does not pay to ignore the red flags; and yet we so often do.

Mistake: Not doing your research. In a sense that is seemingly contradictory to the "trust your gut" idea, some mistakes come from not having conscientiously examined the situation. As with many other issues, these situations can appear in a number of different contexts and with varied stakeholders. As in an example cited elsewhere in this paper, not being persistent in asking questions during the interview process can lead to unpleasant surprises. In another programmatic situation, an interviewee spoke of a time early in his career when

...we booked a tour of a group to Indonesia in 1998. Just before the group left to go to Indonesia, there was some rumbling; I can't remember the dictator that was in power, it was so long ago. Someone on campus contacted me and said, "Have you been watching this?" And I said, "Well, yeah, sort of." And he said, "I think you ought to be a little more worried about this." So I called the US embassy in Djakarta. I asked about it and the guy that I talked to said something to the effect of, "You don't really need to worry about coming to Indonesia. In fact, there is probably not a better time for Americans to come than right now." So based on that and some other things, we sent the group. The day after they got there, it broke out into a shooting civil war. We moved the group to this Club Med type place on suburbs of Jakarta. They had a great time. They were in a gated hotel, they didn't 
have to leave, it had a swimming pool. They just played for a week. Unsurprisingly my bosses were concerned that I had put the group into that situation. So that was a mistake, but then I was able to pull out this information I got from the State Department and say, "Look, I made the best guess from the information." That probably saved my job. I felt if I had not had that, there's a chance I would have been fired.

Not asking enough questions also led to an important misunderstanding when a study abroad adviser unquestioningly accepted a student's concerns at face value:

A student was having second thoughts about whether to go to a study abroad program. She stated financial concerns so I alleviated those for her and her mother and encouraged her to go. Shortly after the semester in Spain began, the student basically had a nervous breakdown creating a huge burden for the host family and program director not to mention the student and her family...

In this case, the money issue was standing in for something else. The advisor did not see any indication that there might be something else, but she learned to look more deeply.

Sometimes, we are pressured for decisions and it is hard to delay giving a response until we have thoroughly researched the issue. But rushing to answer can be a mistake, whether it's a student, colleague, or someone else involved. In one situation, a respondent speaks of students whose impatience for information have led her to make "a mistake I make too many times":

A student will come in without an appointment and say he/she has a quick question. In trying to answer it quickly, or on the fly, I might not have all the information or I might rush to answer. I have given out bad immigration advice simply because I did not have all the information....

Of course, it's not just students who provoke us to respond too quickly. A colleague of a respondent asked her to skip the protocol, to which she agreed, with unfortunate repercussions.

A friend and colleague asked me not to follow the usual protocol to get things done. I agreed to do so. I did not see the reason to skip the protocol, but I did it anyway. As a result, there were factors that I did not consider and other colleagues did not get the opportunity to be part of the event. ... I went along with my colleague and ignored protocol because I could see no harm. I did it not because I carefully considered the action but because I wanted to be agreeable.

Yes, being agreeable is often the motivation to give an answer, yet it has been a mistake for many. In the end, it has led to disgruntled employees and students, embarrassed international educators, and even unhappy job situations.

Mistake: Not questioning assumptions. Sometimes we make decisions based on our own assumptions, which may seem to us as perfectly obvious and rational, but which prove not to be so. In one challenging example, a participant overlooked an important visa detail regarding a Canadian because she assumed that what was true for US Americans would be for this participant:

We had a Canadian on a short term program to Eastern Europe. The Americans did not need visas to enter any of the countries and I thought that the same must also be true for 
Canadians (I mean really, aren't we the same?). Turns out that at that time Poland had an agreement with the United States on allowing Americans to enter without a visa, but not so with Canadians. We spent a tense hour or so at the border convincing the border guard to let the lone Canadian enter the country....

As international educators working with US students, we are aware of the assumptions that many have that the legal systems they encounter will respect the traditions we hold. And as we know, that isn't true; often we learned that reality through our own misinformed experience:

When I first went abroad, I thought the Constitution protected me overseas! Though this seems a strange thought to me now, I made the mistake of assuming that U.S. laws protected U.S. citizens around the world .... Though I never got in trouble overseas, I learned that U.S. laws cannot protect you overseas.

Another respondent wrote about her misinformed assumptions about students' sense of responsibility and thoroughness, assuming that program participants had “. . . read meticulously all of the pre-departure Orientation materials, including the subtle pieces on cultural differences as well as the concrete program policies."

Sometimes, the assumptions are about co-workers. It could be counting on the "good will of a colleague" [from another culture], as one participant noted, “... assuming that she would want to help me out with a difficult situation as much as I would want to help her in a similar situation." In a similar vein, other individuals assumed that everyone would be as enthusiastic as the boss who hired her to make changes (but they weren't); that the organization would work by the espoused values of its programs (but it didn't); or that the supervisor understood the situation (but he didn't). Each one of these situations took significant effort to "clean up."

It is easy in retrospect to see the folly of our assumptions, yet at the moment we make them they may not seem misguided.

The lessons: So what do we do? When do we trust out gut? When do we do more research? How do we ferret out our erroneous assumptions? The lessons that come out of these mistakes are valuable indeed. I use the participants' own words to capture their lessons.

- Lesson: Be aware of one's intuition and the signs that spark a concern. As one person, wrote, "[the lesson is to ...] trust my instincts and then use data to make my case." Another noted, "[my gut] has almost always been right." And a third said she would "[intervene] when [she] sees a red flag." Participants in the study focused particularly on working with students in this regard. Many spoke about engaging the student in question in a dialogue about the issues and the ramifications of potential or real misbehaviors or concerns:

- In the situation with the disruptive student who had already been in the host country and was co-opting the resident director's role and disrupting the other students' experience, she (the resident director) wishes she had had a private conversation with the student and asked him to "Let them discover for themselves."

- "I now will take students aside after orientation if there are any red flags and discuss the situations and the impacts on health/safety, the group, themselves, the university...”. 
○ "I have learned to treat even the most vague emails as calls for attention or for help with an issue and not to auto-prioritize issues by least to most important: all issues are usually important to the student writing, even if the initial email doesn't make it sound like that."

In other situations, the intervention must go beyond a conversation. With respect to the girl with severe anxiety issues, the resident director told me that, "As it was obvious she was unable to cope, I should have arranged for her to see a psychiatrist very early and had the psychiatrist speak with my dean about the situation."

- Lesson: Take the time to dig deeper and to consider the situation more fully. Surfacing better understanding of a potential job, a student's concerns and fears, the nuances of a precarious situation, or other considerations that may not be obvious will lead to better decisions and actions. As one wrote:

In hindsight I learned that the concerns stated by a student may not be the true ones and may hide a bigger, more serious, issue that the student may not want to voice with me or may not even be aware of consciously ... . I now listen to students' concerns and try to get at the root of the issue if they will talk.

The international educator who sent a musical group into what turned out to be a dangerous situation in Indonesia now tells his colleagues:

"You might be tenured, but if you put students into a [dangerous] situation, probably not a lot of that is going to matter, because the university will find a way, and if you're at the end of that .... You really need to be careful." You get the best information possible, and you ought to be skeptical. We're a lot more sophisticated in the information that we get now.

Another wrote about doing more research with others in the institution: "Knowing what I know now, I'm more likely to probe with other departments about 'fishy' behavior, to see if the student has a reputation (even if he's not been sanctioned)."

While investigation fully takes more time, that temporal (and sometimes emotional) distance will often help one get a better, more rounded view:

I have also learned to step back from student anxiety, keep myself calm, try to express sympathy and not react to tantrums or outbursts. Learning not to react to student anger, anxiety or sadness is sometimes a challenge, but I have become much better at disengaging but remaining sympathetic.

As another wrote, 'I learned to never let a student bully me into 'guessing' at an answer. It is best to gather information before responding even if it takes an extra day."

- Lesson: Clarify and articulate assumptions, and then intervene. In order to develop and share a wellgrounded understanding of the circumstances, it is first important to be aware of the assumptions one is making. But how does one know when making assumptions? How was the professional working with the US Embassy in Djakarta to know that the information he received was not enough? In other situations, participants in this study found themselves tripped up in cross-cultural situations where they did not realize the limitations of their assumptions. At times, one learns caution from difficult experiences. Having discovered that she could not count on the 
good will of her colleague, an international educator learned that "Trust is something that is earned." Another uses her own mistaken assumptions to help students understand "the ways laws work overseas." A third, no longer trusting that students have read and understood the important materials her office provides, "created a shorter initial \& signature form with the most important issues highlighted, with a place to initial next to each highlighted issue."

Overarching lesson: Design strong student-centered programs that take advantage of the location, and which are holistic, reflective and experiential. Everyone wants to develop strong programs, whether on the home campus or abroad. Participants in this research have identified actions they have taken that led to negative repercussions, and the learning that ensued for them, which now enable them to create better learning opportunities. Some of the mistakes and lessons are very specific, while others apply more broadly. As with the other areas, some of the mistakes included here led to learning that extends beyond just this category.

Mistake: Having inaccurate or unrealistic expectations of students. Challenges in working with students involve both the staff (teacher-educator-administrator) and the student. Sometimes, the balance of responsibility is legitimately tilted toward the "difficult" student and the professional needs to determine how best to respond. In other situations, the educator has perceived students inaccurately or unfairly and must revisit his or her assumptions and perspectives.

We'll begin here with the educator who has misread, misunderstood, or misconstrued the students with whom he or she is working. Seeing students erroneously not only frustrates the students, it can also thwart the learning that students are supposed to be experiencing and create extra stress for faculty and administration.

In some cases, the mistake comes from being blind to important information. One resident director wrote about underestimating the leadership potential of students. Another international educator allowed a multi-million dollar proposal to go through even though there was no student interest.

In other cases, it may be about trying to fit students into a mold that is unfair and limiting. A study abroad administrator who had recently changed jobs from a socially-minded third party provider to a campus international education office, carried with him a set of expectations that did not fit the students:

I got to [the new job], and instead of seeing [the university] students for who they are, I saw them for who I wanted them to be .... I had almost a disdain for who they were. They're not interested in politics. They're kind of indifferent. This was my passion. I wasn't as effective [as I could have been].

Two resident directors made a similar mistake, making assumptions about what students would find engaging, continuing to force upon them a curriculum that didn't match their interests or knowledge base. In one case, the program leader found the students to be overstressed when she compelled them to stretch themselves in ways that were beyond them: "I misjudged how much new stuff they could handle (in addition to a new language and a new culture)."

In the second case, the educator simply wrote, "the students hated the class." 
Mistake: Not dealing well with difficult students. Sometimes, the challenge resides with the student. Seemingly, all of us have encountered certain behaviors that have challenged us: not following rules, perhaps, or asking the hardest questions, or showing disrespect for the culture, other students, or oneself. Especially when life is busy and stressful, it is tempting to merely "wish away" the problems generated by these individuals. But that rarely, if ever, works. In a situation mentioned in the section on "trusting one's gut," a resident director described how she did not respond as soon as she sensed that something was amiss with a student who had been to the host country before and tried to countermand her leadership. As mentioned there, that student's troublesome behavior affected the entire group, and the resident director regrets now not having acted early on.

Sometimes, students push us to make exceptions and we may come to "pay" for acceding to their demands. A resident director spoke of a challenging situation when she didn't act according to the guidelines established for research in the host country. A student had wanted to do research on "issues of oil - very protected area in terms of investigation or research," a topic which required clearances. The RD thought she could make an exception because of her network, but indeed they discovered they did need clearance in the middle of the student's project. In the end, making the exception ended up impeding the student's project.

Yet it is also possible to be too strict about the rules, and an exception is warranted:

A student engaged in serious misbehavior involving property damage and personal injury during his first week on our semester program. I advocated sending him home but was overruled. He stayed on, under severe restriction, and became a model student in the program.

Mistake: Not engaging the host community in a positive and respectful way. Study abroad programs exist within host communities and can become isolated and separated unless the connections are positively facilitated. Most international educators have "war stories" of disrespectful students (or even faculty) who disregarded community values. The participants in this project are no different. As mentioned in the section on assumptions, it is not uncommon to assume that the US Constitution and laws will protect one when overseas. Another mistake was that of the program leader who didn't engage the host community in resolving a difficult situation:

While serving as resident director abroad, I accused a local neighbor of sexually harassing a US student. The student claimed he had tried to kiss her and would not leave her alone after she refused him. I told him he could not enter the study center. He did not obey. I then asked his head of household to move his snack stand away from the center. Multiple shouting matches ensued and he expressed anger for being "falsely accused" and not having an opportunity to express his side. The situation only escalated. . .

The story about the student wanting to do research on a topic that was sensitive in the local context also has relevance here. Respect for the community can mean following local standards and laws, not to mention cultural norms. Virtually every international educator has multiple stories about being unintentionally disrespectful, either through our own actions or those of program participants, for whom one has some responsibility. 
Mistake: Not fully considering the situation; being inflexible or too limited in design. Designing a study abroad program takes a special set of competencies, often developed over a period of trial and error. Participants spoke abundantly about the mistakes they had made.

- Being a slave to the schedule. A beginning RD was excited about an exercise that took place outside early in the program and he stayed wedded to the idea, even in spite of rain that came and his own suspicion that maybe he should postpone. Students were miserable and did not want to talk to anyone. The exercise, in his words, "completely failed." He was not attuned to the students' mood and, in the end nobody understood the activity.

- Being too linear: using an on-campus model when in the field. Instead of taking advantage of the holistic learning possible in the location, a faculty leader "sequenced the curriculum in the same linear way I might do with a longer on-campus course . . the conceptual part of the class that provided constructs for analyzing experience was too linear and deductive." In a similar situation, a respondent wrote, "the primary text should be the location. The result is that students spend time, which could be spent learning the new culture they are in, sitting in their rooms reading."

- Being too focused on one thing. Faculty leaders, either because of their own abiding interests or because they want to fit in as many on-site opportunities as possible, may not choose their locations carefully. One respondent said it clearly:

It is possible to have too much of a good thing: Unless the program is focused on castle architecture, I have noticed that students quickly tire of seeing castles. Likewise, [this is true of] art museums, history museums, military museums, cathedrals, stately homes, etc. Seeing one monastery after another can become monotonous and students can lose enthusiasm.

And a few other random and specific mistakes. While the errors mentioned above can be captured in a larger "inflexibility" grouping, participants mentioned a few very specific mistakes: not feeding students at strategic times, handling housing so late that only unacceptable options remained, and not handling roommate situations carefully.

As a professor of international education, I sometimes wonder if I can give students a list such as this and prevent mistakes. Yet perhaps these errors (or ones very much like these) are inevitable.

The lessons: These mistakes offer important lessons to us as international educators - regardless of whether we are just staring out in the field or have been in it for decades.

Lesson: Honor and respect the community. Hear the voices, especially in difficult situations and respect host country standards and practices.

- The director who handled the sexual harassment charges poorly wrote, "I should have gathered the student and the neighbor, along with others, to a circle discussion so that everyone could be heard and concerns addressed ... my obligations were not only to my US students, but also to the surrounding community." In addition she expressed her sadness and disappointment about how uncaring she was.

- In the case of the student who wanted to do research that was sensitive and required special clearance, the director said, "I should have told him, you cannot research oil. [While] I think it's 
important to let students have opportunities, if their plan is not feasible, they can do plan b, plan c."

Lesson: Honor and respect the students. Having a narrow set of expectations adds a barrier to the potential for learning and growth that study abroad can offer. Take the time to uncover student interests and competencies and build from there. As one educator said, "I realized that I needed to change and get off my high horse of who I thought the students should be." Allow students to surprise you as leaders and as adults who can change and grow.

Lesson: Stay flexible and create a program that fits the context. Modify your curriculum as the situation and the opportunities allow. Don't be a slave to the schedule. Instead, seek ways to foster learning that can build on the setting. One respondent wrote eloquently:

I tell faculty leading programs that the primary text should be the location they are at and that as much learning as possible should come from "reading" the local architecture, language, customs, historical sites, etc.

Another, concerned with overdoing "too much of a good thing," offered the following advice:

Seeing one monastery after another can become monotonous and students can lose enthusiasm. However, if one can mix it up with a museum thrown in, or a walk in the country, it gives the students a chance to differentiate between the various things they see and to more better internalize what they are learning.

And the very specific tips: Feed the students when you're asking them to do evaluations; see to housing placements early; manage peer-to-peer relationships closely in housing.

\section{Conclusions}

Our lives and lessons are not easily squeezed into categories, these or others. In the context of this research, the same experience typically yielded lessons in more than one area. A difficult student, for example, could be best handled with a well-designed program, a balanced and flexible leader, and careful and positive attention to the variety of relationships. And the difficulties they are bringing up could have been signaled by a "red flag" last week or month. A stressed-out colleague might be supported by careful policies and procedures and some time to reflect and regain his balance.

And speaking of stressed-out colleagues, the last lesson speaks to the need to take care of oneself.

Overarching lesson: It is important to take care of yourself, to seek and maintain balance. It is easy for international educators to feel consumed by their jobs, often because of the intensity of the interactions with students who themselves may be facing major questions and challenges. One international educator reflects about the beginning of her career by saying, "In early days, as on-site staff, working with many students each semester in a challenging environment, I gave all of myself to their success, wellness, and development."

Other respondents shared similar stories, leading to feeling off-balance, isolated and burned out. One, who worked with international students, shared: 
In my first professional role, I was in charge of planning activities and events for international students and cultural events for the entire campus. I had many late night events and odd hours. My mistake is that I didn't have any boundaries between my work and personal life and I did not have time to build a professional network. My friends became my international students.

Study abroad directors have reported the same kinds of issues as they traveled with a group of students away from home. Cross-cultural situations are often stressful, which can lead to less-thanfunctional behavior for all involved, including trying to protect students from what could be a powerful learning experience, what one called "a young adult's strongest developmental process - experiencing, making mistakes, reflecting and learning from them." As one respondent said:

I ... learned that it is possible to intervene too much -- importance of letting go of the outcomes and supporting students as they create their own experience, paved with mistakes and lessons, and making space to reflect on the process, individually and in groups, is essential to deep and sustained learning.

The lessons. So what did they learn? The responses are very similar: take better care of oneself. As quoted above, one noted that she had learned to “... step back [and] keep [herself] calm ... disengaging but remaining sympathetic." Another wrote that she learned that she needed to "put an oxygen mask on myself before helping others (or at least at the same time), also modeling self-care and sustainability for students." And an interviewee spoke about how important it was to reflect in her journal and to revisit the reflections later. And another expressed a similar feeling, focusing on how to support students without being over-engaged:

I have also learned to step back from student anxiety, keep myself calm, try to express sympathy and not react to tantrums or outbursts. Learning not to react to student anger, anxiety or sadness is sometimes a challenge, but I have become much better at disengaging but remaining sympathetic.

In conclusion, the work of an international educator is challenging, due to complex situations across multiple cultures, conflicting values, and paradigm-pushing educational encounters. It is to be expected that these professionals will make mistakes. The overarching lesson here is that we should not be fearful of tripping up, but rather be open to learning from the mistakes we make. Granted, our workplaces and institutions must honor and support us as we err and stumble, and, for some of us, that is unlikely. But perhaps, as we learn more about the value of learning through our mistakes, we will find a greater welcome for experimentation.

\section{References}

Accountemps. (2012). Workplace frights: Survey reveals workers are most afraid of making a mistake [Press release]. Retrieved from http://accountemps.rhi.mediaroom.com/workplace-fears

Antony, M. and Swinson, R. (2009). When perfect isn't good enough Strategies for coping with perfectionism. $2^{\text {nd }}$ ed. Oakland: New Harbinger Publications.

The Forum on Education Abroad. (2013). Constructing Effective U.S. - Brazilian Partnerships Forum FAUBAI Report. Carlisle, PA: The Forum on Education Abroad.

Holden, C. (2007, December 7). Gene variant may influence how people learn from mistakes. Science 318 (5856), 1539.

Hoye, W. P. (2006, February). Legal issues influencing international study abroad programs. Paper 
presented at the 27th Annual National Conference on Law and Higher Education, Clearwater Beach, FL.

Kwintessential. (2014). Country profiles - global guide to culture, customs and etiquette.

Kwintessential. Retrieved August 12, 2015 from

http://www.kwintessential.co.uk/resources/country-profiles.html.

Laufenberg, D. (2010). How to learn? From mistakes [Video file]. Retrieved from: http:/ /www.ted.com/talks/diana_laufenberg_3_ways_to_teach?language=en

Lehrer, J. (2009, December 21). Accept defeat: The neuroscience of screwing up. . Retrieved from: http://www.wired.com/2009/12/fail_accept_defeat/all/

Livio, M. (2013). Brilliant blunders: From Darwin to Einstein - colossal mistakes by great scientists that changed our understanding of life and the universe. New York: Simon and Schuster.

McGregor, J. (2006, July 10). How failure breeds success. Business Week, pp. 42-52.

Molinsky, A. (2013). Global dexterity: How to adapt your behavior across cultures without losing yourself in the process. Cambridge, MA: Harvard Business Press.

Palmer, P. J. (1997). The courage to teach. San Francisco: Jossey-Bass.

Peace Corps. (2010). Cultural gaffes beyond your borders. Retrieved from: http://www.peacecorps.gov/wws/videos/beyond-borders/

Schoemaker, P. (2011). Brilliant mistakes: Finding success on the far side of failure. Philadelphia: Wharton Digital Press.

Schon, D. (1984). Educating the reflective practitioner. San Francisco: Jossey- Bass.

Senge, P. (1990). The fifth discipline. New York: Doubleday.

Tugend, A. (2011). Better by mistake: The unexpected benefits of being wrong. New York: Riverhead.

Ullsperger, M. (2008). Minding mistakes: How the brain monitors errors and learns from goofs. Scientific American, 19, 52-59. doi:10.1038/scientificamericanmind0808-52

Williams, R. and Branco, S. (2014). Brazil-Culture smart. London, UK: Kuperard 